\title{
Associations of Alcoholic Beverage Consumption with Dietary Intake, Waist Circumference, and Body Mass Index in US Adults: National Health and Nutrition Examination Survey 2003-2012
}

\author{
Lauren Butler, PhD, RDN, LDN; Barry M. Popkin, PhD; Jennifer M. Poti, PhD
}

\section{ARTICLE INFORMATION}

Article history:

Submitted 21 December 2016

Accepted 28 September 2017

Available online 22 December 2017

\section{Keywords:}

Alcoholic beverage consumption

Body mass index

Waist circumference

Supplementary materials:

The Figure and Table 3 are available at www. jandonline.org

\begin{abstract}
Background Findings from studies of alcohol and obesity measures (eg, waist circumference [WC] and body mass index [BMI; calculated as $\left.\mathrm{kg} / \mathrm{m}^{2}\right]$ ) are conflicting. Residual confounding by dietary intake, inconsistent definitions of alcohol consumption across studies, and the inclusion of former drinkers in the nondrinking comparison group can contribute to the mixed literature.
\end{abstract}

Objective This study examines associations of alcoholic beverage consumption with dietary intake, WC, and BMI.

Design Cross-sectional data from the 2003-2012 National Health and Nutrition Examination Survey were analyzed.

Participants/setting Adults 20 to 79 years of age ( $n=7,436$ men; $n=6,939$ women) were studied.

Main outcome measures Associations of alcoholic beverage consumption with energy (kcal), macronutrient and sugar intakes (\% kcal), WC, and BMI were determined.

Statistical analyses performed Multivariable linear regression models were used to determine associations of average daily volume and drinking quantity (ie, drinks per drinking day) with dietary intake and obesity measures. Former and never drinkers were analyzed as distinct categories; associations of drinking with WC and BMI were examined with and without adjustment for dietary intake variables.

Results Heavier-drinking men ( $\geq 3$ drinks/day) and women ( $\geq 2$ drinks/day) consumed less nonalcoholic energy ( $\beta-252 \mathrm{kcal} / \mathrm{day}, 95 \% \mathrm{CI}-346$ to $-159 \mathrm{kcal} / \mathrm{day}$ and $\beta-159 \mathrm{kcal} /$ day, $95 \% \mathrm{Cl}-245$ to $-73 \mathrm{kcal} /$ day, respectively) than moderate drinkers ( 1 to 2 drinks/day in men and 1 drink/day in women). By average daily drinking volume, differences in WC and BMI between former and moderate drinkers were $+1.78 \mathrm{~cm}(95 \% \mathrm{CI} 0.51$ to $3.05 \mathrm{~cm})$ and +0.65 (95\% CI 0.12 to 1.18 ) in men and $+4.67 \mathrm{~cm}(95 \% \mathrm{Cl} 2.95$ to $6.39 \mathrm{~cm})$ and +2.49 (95\% CI 1.64 to 3.34 ) in women. Compared with moderate drinking, heavier drinking volume was not associated with WC or BMI among men or women. In men, drinking $\geq 5$ drinks/drinking day was associated with higher WC $(\beta 3.48 \mathrm{~cm}, 95 \% \mathrm{CI} 1.97$ to $5.00 \mathrm{~cm})$ and $\operatorname{BMI}(\beta 1.39,95 \% \mathrm{CI} 0.79$ to 2.00$)$ compared with men who consumed 1 to 2 drinks/drinking day. In women, WC and BMI were not significantly different for women drinking $\geq 4$ drinks/drinking day compared with 1 drink/drinking day.

Conclusions Differences in dietary intake across drinking subgroups and separation of former drinkers from nondrinkers should be considered in studies of alcohol intake in relation to WC and BMI.

J Acad Nutr Diet. 2018;118:409-420.

\footnotetext{
I
} N 2015, 56\% OF ADULTS IN THE UNITED STATES REported alcoholic beverage consumption in the past month and $30.4 \%$ of those aged 20 years or older were considered obese. ${ }^{1,2}$ There is a wealth of conflicting epidemiologic findings regarding the relationship between alcoholic beverage consumption and obesity measures, such as waist circumference (WC) and body mass index (BMI; calculated as $\mathrm{kg} / \mathrm{m}^{2}$ ). Residual confounding by dietary intake, inconsistent definitions of alcoholic beverage consumption across studies, and the inclusion of former drinkers in nondrinking referent 
groups, have been cited as potential reasons for contradictory findings across the alcohol and obesity literature. ${ }^{3-7}$

Alcoholic beverage consumption has been linked to poor diet quality; altered dietary composition; and lower intake of carbohydrates, sugar, and select food and nonalcoholic beverage groups compared with abstention..$^{8-11}$ It has been suggested that drinkers might replace food (ie, energy from solid foods) and nonalcoholic beverages with alcoholic beverages. This replacement would, in part, be evidenced by lower intake of foods and nonalcoholic beverages in drinkers compared with nondrinkers. ${ }^{8,9,12-15}$ Among drinkers, consuming $\geq 3$ drinks/day has been associated with higher total energy intake compared with those who consumed $<1$ drink/day. ${ }^{8}$ Yet, associations between alcoholic beverage consumption and food, nonalcoholic beverages, macronutrient, and sugar intakes are not well understood. ${ }^{16}$

Positive, inverse and null findings have been reported across studies of alcohol and obesity measures. $4,6,13,14,17-21$ Residual confounding by dietary intake has been cited as one reason for conflicting findings because some studies fail to adjust for dietary components as confounders in statistical analyses. ${ }^{4,17,21,22}$ In addition, inconsistencies in the definitions of alcoholic beverage consumption used across studies, and the inclusion of former drinkers in the nondrinking comparison group, have been hypothesized to contribute to contradictory findings in the literature. ${ }^{4-6,23}$ Generally, alcoholic beverage consumption is defined as average daily drinking volume (calculated as quantity $\times$ frequency)., ${ }^{63}$ Some studies of alcohol and obesity measures define alcohol intake in terms of quantity or frequency alone. ${ }^{6}$ Recent research examining associations of average daily volume and drinking quantity with BMI indicate that using average daily drinking volume alone can mask associations of higher quantities with higher estimates of BMI compared with those who consume less per drinking occasion. ${ }^{6}$ Further, the inclusion of former drinkers in the nondrinking comparison group has been hypothesized to contribute to contradictory findings in the literature. ${ }^{4-6,23}$ Nondrinking subgroups typically include never drinkers as well as former drinkers, who might have stopped drinking due to ill health or other conditions associated with higher WC and BMI compared with drinkers. ${ }^{5,23,24}$ The extent to which the inclusion of former drinkers in nondrinking subgroups can bias study results is unknown. Moreover, few studies have examined differences in WC and BMI in drinkers compared with former and never drinkers using average daily volume and quantity to define alcohol intake.

The overarching aim of this study was to determine the associations of alcoholic beverage intake with WC and BMI. To better understand relationships between alcohol and dietary intake, associations of alcoholic beverage consumption with total energy, nonalcoholic energy (food plus nonalcoholic beverages), food, nonalcoholic beverages, and macronutrient and sugar intakes were determined. To shed light on inconsistencies in the alcohol obesity literature, alcoholic beverage consumption was defined as average daily volume and average quantity (ie, number of drinks on drinking days), former and never drinkers were analyzed as distinct categories, and relationships of alcoholic beverage consumption with WC and BMI were examined with and without adjustment for dietary intake variables.

\section{METHODS}

The National Health and Nutrition Examination Survey (NHANES) is a repeated, cross-sectional survey of the civilian, non-institutionalized US population administered by the National Center for Health Statistics division of the Centers for Disease Control and Prevention and US Department of Agriculture. The NHANES utilizes a multistage, stratified area probability sampling design to select participants representative of the US population. NHANES combines in-person interviews and physical examinations via a mobile examination center. NHANES collects lifetime and current alcohol use data (alcohol use during the past 12 months) for respondents $\geq 20$ years of age as part of the mobile examination center examinations using an Alcohol Use Questionnaire. ${ }^{25-29}$ NHANES dietary recalls are interviewer-administered using the US Department of Agriculture (USDA) Automated Multiple-Pass Method and include one in-person 24-hour dietary recall and a second recall collected 3 to 10 days later by phone. ${ }^{30-34}$ The mobile examination center physical examinations include anthropometric measurements of height, weight, and WC administered by trained professionals. ${ }^{35}$ Sociodemographic and physical activity data from all surveys were obtained via trained intervieweradministered questionnaires. Details related to the collection of these data can be found through the Centers for Disease Control and Prevention. ${ }^{30-34}$

During the mobile examination center examination, participants are asked the following questions: 1) "In any one year, have you had at least 12 drinks of any type of alcoholic beverage?"; 2) "In your entire life, have you had at least 12 drinks of any type of alcoholic beverage?"; 3) "In the past 12 months, how often did you drink any type of alcoholic beverage?"; and 4) "In the past 12 months, on those days that you drank alcoholic beverages, on the average how many drinks did you have?" Respondents who answered "yes" to drinking at least 12 alcoholic drinks in the past year or in their entire lifetime and had consumed alcohol on at least 1 day in the past year were considered current drinkers. Respondents who answered "no" to drinking any alcohol in their entire lifetime and in the past 12 months were coded as "never drinkers." Respondents who answered "yes" to drinking in their entire lifetime, but had not consumed alcohol in the past 12 months were coded as "former drinkers." Alcoholic beverage consumption was defined using two variables: average daily drinking volume (quantity $\times$ frequency/365) and average quantity (drinks/drinking day). Drinkers were further categorized into sex-specific drinking categories because men and women differ in the amounts of alcoholic beverages they consume. ${ }^{8,17,21,36}$ Average daily drinking volume was categorized based on the 2015-2020 Dietary Guidelines for Americans ${ }^{37}$ moderate drinking recommendations as follows: men were classified as light drinker ( $<1$ drink/day; operationally $<0$ to 0.49 drinks/day), moderate drinker ( 1 to 2 drinks/day; operationally 0.5 to 2.49 drinks/day), or heavier drinker ( $\geq 3$ drinks/day; operationally $\geq 2.5$ drinks/day); women were categorized as light drinker ( $<1$ drink/day; operationally $<0$ to 0.49 drinks/day), moderate drinker ( 1 drink/day; operationally 0.5 to 1.49 drinks/ day), or heavier drinker ( $\geq 2$ drinks/day; operationally $\geq 1.5$ drinks/day). Quantity of alcohol intake was defined as 1 to 2, 3 to 4 , and $\geq 5$ drinks/drinking day for men and 1, 2 to 3, and $\geq 4$ drinks/drinking day for women. According to NHANES 
analytic guidelines, reports of $<1$ drink/drinking day were rounded up and coded as 1 drink/drinking day. ${ }^{25-29}$

Dietary intake data were utilized from the What We Eat in America portion of NHANES. USDA nutrient information for What We Eat in America comes from the USDA Food and Nutrient Database for Dietary Studies, based on nutrient values in the USDA National Nutrient Database for Standard Reference. ${ }^{38}$ Because individuals typically consume alcoholic beverages (which contain ethanol as well as nonalcoholic components), not ethanol alone, this study focuses on alcoholic beverages (not ethanol) and aimed to examine how dietary intake, apart from alcoholic beverages, was different by drinking levels. Thus, the nonalcoholic components of alcoholic beverages were included in the total energy intake variable, but were excluded from the nonalcoholic energy, food and nonalcoholic beverage energy, and macronutrient and sugar variables, because these variables were calculated from food and nonalcoholic beverages only. Nonalcoholic beverage intake was calculated as the sum of kilocalories per day (kcal/ day) from all beverages, excluding beer, wine, liquor, and mixed drinks. Food intake was calculated as the sum of all foods consumed (kcal/day). Nonalcoholic energy intake was calculated as the sum of nonalcoholic beverages plus food intake (kcal/day). Macronutrient intakes were calculated as the sum of the grams of each macronutrient from food and nonalcoholic beverages, multiplied by $4 \mathrm{kcal} / \mathrm{g}, 4 \mathrm{kcal} / \mathrm{g}$, and $9 \mathrm{kcal} / \mathrm{g}$ for carbohydrates, protein, and fat, respectively. Sugar intake was calculated as the total grams of sugar from food and nonalcoholic beverages multiplied by $4 \mathrm{kcal} / \mathrm{g}$. Two carbohydrate intake variables were calculated: one with and one without sugar intakes. The contribution of macronutrients and sugar from nonalcoholic sources to intake were calculated as percentages of total energy intake, in accordance with previous studies. ${ }^{39-44}$ All dietary intake variables were calculated from the average of two 24-hour dietary recalls. Implausible energy intakes are an inherent limitation of using dietary recall data to estimate energy intakes. ${ }^{45-47}$ The revised Goldberg method was used to identify implausible energy intakes and categorize adults as potential dietary under-reporters, over-reporters, or accurate reporters, as described in the Supplemental Methods and Analyses (Figure; available online at www.jandonline. org). ${ }^{47-52}$

Body height, weight, and WC (measured midway between the lowest rib margin and the iliac crest at the mid-axillary line) were measured (height to the nearest $0.1 \mathrm{~cm}$ via SECA stadiometer, weight measured to the nearest $0.1 \mathrm{lb}$ and converted to kilograms via Toledo digital scale, $\mathrm{WC}$ to the nearest $1 \mathrm{~mm}$ via measuring tape). BMI was calculated as weight in kilograms divided by height in meters squared $(\mathrm{kg} /$ $\mathrm{m}^{2}$ ). The University of North Carolina Institutional Review Board determined that this submission does not constitute human subjects research as defined under federal regulations [45 CFR 46.102 (d or f) and 21 CFR 56.102(c)(e)(l)] and does not require Institutional Review Board approval.

\section{Statistical Analyses}

All analyses used survey commands within Stata, version 14, to account for complex survey design and incorporate survey weights. ${ }^{53}$ Analyses were stratified by sex and included the following covariates: age group (20 to 39,40 to 59 , and 60 to 79 years), race/ethnic group (non-Hispanic white,
non-Hispanic black, Mexican American, Hispanic, and other races/ethnicities), education (less than high school, high school graduate, some college, or college graduate), family income based on the federal poverty level (FPL) thresholds for supplemental assistance programs available to adults ( $0 \%$ to $130 \%$ FPL, $131 \%$ to $299 \%$ FPL, and $\geq 300 \%$ FPL), smoking status (current, never, or former), marital status (single/never married, formerly married, currently married/cohabitating), average hours of sedentary activity per day (continuous), potential dietary misreporting status (over-reporter, accurate reporter, and under-reporter), survey year of data collection (2003 to 2004, 2005 to 2006, 2007 to 2008, 2009 to 2010, and 2011 to 2012), self-reported history of major chronic disease (cardiovascular disease, stroke, or cancer [yes or no]), day of first dietary recall (weekend [Friday through Sunday] or weekday [Monday through Thursday]), day of second dietary recall (weekend/weekday), and physical activity level (low, moderate, high). A brief description of how physical activity was categorized can be found in the Supplemental Methods and Analyses (Figure; available at www.jandonline.org).

Alcohol intake data are only available for individuals $\geq 20$ years and older. Respondents aged $\geq 80$ years were excluded because their exact age is not provided due to disclosure risk $(n=1,736)$. Further, the exclusion of participants $\geq 80$ years of age helps avoid variation in the associations of interest related to age-related loss of lean muscle mass and increased likelihood of subclinical disease among older adults that may affect weight. Thus, the current study subsample was derived from adults aged 20 to 79 years with complete alcoholic beverage intake questionnaires and 2 days of dietary recall data deemed reliable by study investigators from five pooled cycles of NHANES from 2003 to $2012(n=19,422)$. Adults missing anthropometric outcomes were excluded (WC, $\mathrm{n}=417$; BMI, $\mathrm{n}=36$ ). Pregnant and breastfeeding women $(\mathrm{n}=582)$ were excluded. To minimize reverse causality, adults who reported following a medical diet $(n=1,429)$ or a weightchange diet (ie, gain or loss) $(n=1,409)$ in the past year were excluded and participants missing complete covariate data $(\mathrm{n}=1,174)$ were excluded. The final analytic sample included 14,375 men $(n=7,436)$ and women $(n=6,939)$.

Because the existing literature suggests that alcohol intake has differential associations with adiposity among men and women, all analyses were stratified by sex. ${ }^{4} \chi^{2}$ tests were used to test whether the survey-weighted unadjusted distribution of categorical covariates in each drinking category differed from the distributions of moderate drinkers. Because of the presence of strata containing only a single primary sampling unit, the survey-weighted distributions of covariates among women in the heavier drinking subgroup were analyzed with and without strata specification. ${ }^{54}$ For continuous variables, pair-wise comparisons were conducted using $t$ tests to compare means in each drinking category with those for moderate drinkers. Statistical significance was defined based on $P<0.05$, with Bonferroni correction for multiple comparisons.

Multivariable linear regression models were used to determine whether alcoholic beverage consumption was associated with diet, WC, and BMI. Outcome variables (continuous) were regressed on alcoholic beverage consumption variables coded as indicator variables $(0 / 1)$. When average daily drinking volume was the independent variable, "moderate drinker" was the referent group. When quantity was the independent variable, 1 to 2 drinks per drinking day (drinks/drinking day) for men and 
Table 1. Survey-weighted distribution of select covariates by sex and average daily drinking volume (drinks/d), National Health and Nutrition Examination Survey 2003$2012^{\mathrm{ab}}$

Average Daily Drinking Volume

\begin{tabular}{|c|c|c|c|c|c|c|c|c|c|c|}
\hline \multirow[b]{3}{*}{ Variable } & \multicolumn{10}{|c|}{ Average Daily Drinking Volume } \\
\hline & \multicolumn{5}{|c|}{ Men } & \multicolumn{5}{|c|}{ Women } \\
\hline & Never & Former & Light & Moderate & Heavier & Never & Former & Light & Moderate & Heavier \\
\hline & & & & & - mean $\pm s$ & ard error- & & & & \\
\hline$\%$ & $6.1 \pm 0.5$ & $14.8 \pm 0.7$ & $40.0 \pm 0.9$ & $30.2 \pm 0.9$ & $9.0 \pm 0.5$ & $14.1 \pm 0.7$ & $15.5 \pm 0.7$ & $52.9 \pm 0.9$ & $13.3 \pm 0.7$ & $4.1 \pm 0.4$ \\
\hline Drinks/d & $0.0 \pm 0.0$ & $0.0 \pm 0.0$ & $0.14 \pm 0.0$ & $1.15 \pm 0.02$ & $4.35 \pm 0.14$ & $0.0 \pm 0.0$ & $0.0 \pm 0.0$ & $0.11 \pm 0.0$ & $0.87 \pm 0.02$ & $2.81 \pm 0.15$ \\
\hline \multicolumn{11}{|l|}{ Age group, y } \\
\hline $20-39$ & $45.1 \pm 3.7$ & $23.1 \pm 1.8$ & $44.2 \pm 1.4$ & $45.2 \pm 1.7$ & $41.7 \pm 3.2$ & $34.7 \pm 2$ & $21.7 \pm 1.6$ & $41.5 \pm 1.3$ & $43.6 \pm 2.7$ & $32.4 \pm 2.6$ \\
\hline $40-59$ & $30.8 \pm 3.3$ & $43.8 \pm 2.1$ & $38.5 \pm 1.2$ & $38.7 \pm 1.7$ & $40.7 \pm 3.4$ & $34.2 \pm 2.2$ & $44.3 \pm 2.4$ & $41.0 \pm 1.2$ & $38.7 \pm 2.6$ & $49.0 \pm 3.8$ \\
\hline \multirow[t]{2}{*}{$60-79$} & $24.0 \pm 3.1$ & $33.1 \pm 1.7$ & $17.3 \pm 0.9$ & $16.1 \pm 1.2$ & $17.6 \pm 2.2$ & $31.2 \pm 1.7$ & $34.0 \pm 2.4$ & $17.5 \pm 0.9$ & $17.7 \pm 1.9$ & $18.5 \pm 2.3$ \\
\hline & 0.0157 & 0.0000 & 0.6722 & \multicolumn{4}{|c|}{-P value } & 0.6831 & & 0.1936 \\
\hline \multicolumn{11}{|c|}{$-m e a n \pm$ standard error- } \\
\hline $\mathrm{NHW}^{\mathrm{c}}$ & $62.7 \pm 4$ & $69.9 \pm 2.5$ & $67.8 \pm 1.9$ & $76.2 \pm 1.5$ & $77.1 \pm 2.3$ & $55.0 \pm 3.3$ & $68.8 \pm 2.4$ & $72.7 \pm 1.7$ & $84.4 \pm 1.5$ & $74.6 \pm 4.8$ \\
\hline $\mathrm{NHB}^{\mathrm{d}}$ & $16.7 \pm 2.5$ & $11.1 \pm 1.4$ & $9.7 \pm 0.9$ & $9.6 \pm 0.8$ & $7.7 \pm 1.1$ & $16.0 \pm 1.8$ & $14.6 \pm 1.6$ & $10.9 \pm 0.9$ & $7.4 \pm 1.1$ & $13.7 \pm 3.3$ \\
\hline Mexican American & $5.1 \pm 1.1$ & $9.5 \pm 1.7$ & $10.0 \pm 1.1$ & $7.9 \pm 1$ & $8.7 \pm 1.4$ & $12.9 \pm 1.7$ & $7.2 \pm 1.1$ & $7.0 \pm 0.7$ & $2.8 \pm 0.6$ & $2.5 \pm 2.0$ \\
\hline Hispanic & $5.5 \pm 1.5$ & $3.8 \pm 0.8$ & $4.9 \pm 0.7$ & $3.3 \pm 0.6$ & $2.8 \pm 0.8$ & $6.1 \pm 1$ & $4.3 \pm 0.7$ & $4.7 \pm 0.6$ & $2.5 \pm 0.6$ & $1.9 \pm 0.2$ \\
\hline \multirow[t]{2}{*}{ Other } & $10.0 \pm 1.9$ & $5.7 \pm 0.9$ & $7.5 \pm 0.8$ & $3.0 \pm 0.5$ & $3.7 \pm 1.1$ & $10.0 \pm 1.5$ & $5.1 \pm 1.2$ & $4.7 \pm 0.5$ & $2.9 \pm 0.6$ & $7.3 \pm 0.7$ \\
\hline & 0.0000 & 0.0170 & 0.0000 & & 0.5511 & 0.0000 & 0.0000 & 0.0000 & & 0.1914 \\
\hline \multicolumn{11}{|l|}{ Education } \\
\hline Less than high school & $18.0 \pm 2.7$ & $25.5 \pm 1.8$ & $15.5 \pm 1.2$ & $11.6 \pm 0.9$ & $20.2 \pm 1.7$ & $26.3 \pm 2$ & $22.7 \pm 1.7$ & $12.0 \pm 0.8$ & $7.1 \pm 1$ & $20.2 \pm 1.2$ \\
\hline High school ${ }^{e}$ & $27.9 \pm 3.5$ & $32.3 \pm 2.4$ & $22.4 \pm 1.4$ & $21.3 \pm 1.3$ & $32.4 \pm 3.1$ & $27.5 \pm 1.9$ & $30.5 \pm 2$ & $22.2 \pm 1.2$ & $20.0 \pm 2.1$ & $23.2 \pm 4.9$ \\
\hline Some college & $28.8 \pm 3.3$ & $27.2 \pm 2.2$ & $30.4 \pm 1.5$ & $32.1 \pm 1.5$ & $30.8 \pm 3.1$ & $27.3 \pm 1.8$ & $30.4 \pm 2.1$ & $33.3 \pm 1.3$ & $33.8 \pm 2.6$ & $29.0 \pm 1.8$ \\
\hline \multirow[t]{2}{*}{ College graduate } & $25.4 \pm 2.8$ & $15.1 \pm 1.5$ & $31.7 \pm 1.6$ & $35.0 \pm 2$ & $16.5 \pm 2.5$ & $18.9 \pm 2$ & $16.4 \pm 1.7$ & $32.5 \pm 1.4$ & $39.1 \pm 3$ & $27.6 \pm 2.0$ \\
\hline & 0.0068 & 0.0000 & 0.0491 & & $\begin{array}{l}\mathrm{P} v a \\
0.0000\end{array}$ & 0.0000 & 0.0000 & 0.0113 & & 0.0516 \\
\hline \multicolumn{11}{|l|}{ Household income $^{f}$} \\
\hline $0 \%-130 \%$ & $23.8 \pm 2.5$ & $23.9 \pm 1.7$ & $19.2 \pm 1.2$ & $14.0 \pm 1.1$ & $24.8 \pm 2.3$ & $32.1 \pm 2.1$ & $31.2 \pm 1.9$ & $18.4 \pm 1.1$ & $14.8 \pm 1.8$ & $25.8 \pm 5.6$ \\
\hline $131 \%-299 \%$ & $31.9 \pm 3.4$ & $34.2 \pm 2.1$ & $24.8 \pm 1.2$ & $24.2 \pm 1.3$ & $28.0 \pm 2.7$ & $32.9 \pm 2$ & $33.9 \pm 1.9$ & $27.8 \pm 1.2$ & $21.7 \pm 2.1$ & $19.8 \pm 1.3$ \\
\hline
\end{tabular}


$1 \mathrm{drink} /$ drinking day for women were the referent groups. Models with dietary outcomes as dependent variables were adjusted for age, race/ethnicity, education, physical activity level, survey year, chronic disease status, day of dietary recall 1, day of dietary recall 2 , smoking, and potential dietary misreporting status. Models with obesity measures as dependent variables were adjusted for age, race/ethnicity, education, marital status, physical activity level, survey year, day of recall 1 , day of recall 2, daily sedentary time, smoking status, income and potential dietary misreporting status.

\section{RESULTS}

The survey-weighted distribution of covariates by sex and average daily drinking volume categories are presented in Table 1.

\section{Associations of Alcoholic Beverage Consumption with Dietary Intake}

Adjusted differences in food and nonalcoholic beverage energy intake by average daily drinking volume compared with moderate drinkers are presented in Table 2 . Among men, never and former drinkers consumed less $(\beta-152 \mathrm{kcal} / \mathrm{day}, 95 \%$ $\mathrm{Cl}-230$ to $-73 \mathrm{kcal} / \mathrm{day}$ and $\beta-62 \mathrm{kcal} / \mathrm{day}, 95 \% \mathrm{CI}-117$ to -7 $\mathrm{kcal} /$ day, respectively) total energy compared with moderate drinkers. Former-drinking men and women consumed more ( $\beta 162 \mathrm{kcal} / \mathrm{day}, 95 \% \mathrm{Cl} 104$ to $221 \mathrm{kcal} / \mathrm{day}$ and $\beta 159 \mathrm{kcal} / \mathrm{day}$, $95 \%$ CI 114 to $203 \mathrm{kcal} /$ day, respectively) nonalcoholic energy compared with moderate drinkers. Compared with moderate drinkers, heavier-drinking men and women consumed fewer calories from nonalcoholic energy sources $(\beta-252 \mathrm{kcal} / \mathrm{day}$, $95 \% \mathrm{CI}-346$ to $-159 \mathrm{kcal} / \mathrm{day}$ and $\beta-159 \mathrm{kcal} / \mathrm{day}, 95 \% \mathrm{CI}-245$ to $-73 \mathrm{kcal} /$ day, respectively). Heavier drinking was associated with lower food intake in men $(\beta-165 \mathrm{kcal} / \mathrm{day}, 95 \% \mathrm{CI}-253$ to $-78 \mathrm{kcal} / \mathrm{day})$ and women $(\beta-129 \mathrm{kcal} / \mathrm{day}, 95 \% \mathrm{CI}-201$ to $-57 \mathrm{kcal} / \mathrm{day})$. Carbohydrates and sugar from foods and nonalcoholic beverages contributed more to total energy intake among never, former, and light drinkers and less to energy intake among heavier drinkers compared with their moderate drinking counterparts.

Adjusted associations of food and nonalcoholic beverage energy intake, macronutrient and sugar contributions by drinking quantity are presented in Table 3 (available at www. jandonline.org). Compared with those who drank 1 to 2 drinks/drinking day, men who drank $\geq 5$ drinks/drinking day consumed more total energy ( $\beta 134 \mathrm{kcal} / \mathrm{day}, 95 \% \mathrm{CI} 69$ to $200)$ and less from nonalcoholic energy sources $(\beta-81 \mathrm{kcal} /$ day, $95 \% \mathrm{CI}-139$ to $-22 \mathrm{kcal} /$ day). Among women, former drinkers had higher total energy intake ( $\beta 42 \mathrm{kcal} / \mathrm{day}, 95 \% \mathrm{CI}$ 3 to $80 \mathrm{kcal} /$ day) and energy from nonalcoholic energy sources ( $\beta 77 \mathrm{kcal} /$ day, 95\% CI 38 to $116 \mathrm{kcal} /$ day) compared with those who drank 1 drink/drinking day.

\section{Associations of Alcoholic Beverage Consumption with WC and BMI}

Average Daily Drinking Volume. Adjusted differences in WC and BMI by average daily drinking volume compared with moderate drinkers are presented in Table 4. In men, differences in WC and BMI in former drinkers compared with moderate drinkers were $+1.78 \mathrm{~cm}(95 \%$ CI 0.51 to $3.05 \mathrm{~cm})$ and +0.65 (95\% CI (0.12 to 1.18), respectively (model 1 ). Associations were strengthened after adjustment for sugar intakes (model 2) and attenuated after adjustment for energy 
Table 2. Adjusted associations of average daily drinking volume (drinks/d) with energy intake (kcal/d), macronutrient and sugar contributions (\%) among men and women 20 to 79 years of age, National Health and Nutrition Examination Survey 2003-2012 ${ }^{a}$

\begin{tabular}{|c|c|c|c|c|}
\hline \multirow[b]{2}{*}{ Variable } & \multicolumn{2}{|c|}{ Men } & \multicolumn{2}{|c|}{ Women } \\
\hline & $\beta$ & $95 \% \mathrm{Cl}$ & $\beta$ & $95 \% \mathrm{Cl}$ \\
\hline \multicolumn{5}{|c|}{ A: Total energy (kcal/d) } \\
\hline Never drinker & -152 & -230 to -73 & -31 & -80 to 19 \\
\hline Former drinker & -62 & -117 to -7 & -2 & -47 to 42 \\
\hline Light & -19 & -67 to 30 & -23 & -60 to 14 \\
\hline Moderate & referent & & referent & \\
\hline Heavier & 72 & -10 to 154 & 34 & -42 to 111 \\
\hline \multicolumn{5}{|c|}{ B: Nonalcoholic energy $(\mathrm{kcal} / \mathrm{d})^{\mathrm{b}}$} \\
\hline Never drinker & 71 & -9 to 151 & 125 & 77 to 173 \\
\hline Former drinker & 162 & 104 to 221 & 159 & 114 to 203 \\
\hline Light & 165 & 113 to 217 & 109 & 73 to 144 \\
\hline Moderate & referent & & referent & \\
\hline Heavier & -252 & -346 to -159 & -159 & -245 to -73 \\
\hline \multicolumn{5}{|c|}{ C: Food energy $(\mathrm{kcal} / \mathrm{d})^{\mathrm{b}}$} \\
\hline Never drinker & 12 & -54 to 77 & 44 & -5 to 94 \\
\hline Former drinker & 100 & 42 to 157 & 68 & 26 to 111 \\
\hline Light & 93 & 48 to 138 & 53 & 15 to 91 \\
\hline Moderate & referent & & referent & \\
\hline Heavier & -165 & -253 to -78 & -129 & -201 to -57 \\
\hline \multicolumn{5}{|c|}{ D: Nonalcoholic beverage energy $(\mathrm{kcal} / \mathrm{d})^{\mathrm{b}}$} \\
\hline Never drinker & 59 & 23 to 95 & 80 & 56 to 105 \\
\hline Former drinker & 63 & 37 to 88 & 90 & 64 to 117 \\
\hline Light & 72 & 53 to 90 & 56 & 37 to 75 \\
\hline Moderate & referent & & referent & \\
\hline Heavier & -87 & -120 to -53 & -30 & -66 to 6 \\
\hline \multicolumn{5}{|c|}{ E: $\%$ fat contribution } \\
\hline Never drinker & -0.74 & -1.67 to 0.19 & 0.28 & -0.7 to 1.25 \\
\hline Former drinker & 1.33 & 0.57 to 2.09 & 1.01 & 0.15 to 1.87 \\
\hline Light & 0.72 & 0.11 to 1.34 & 1.14 & 0.42 to 1.86 \\
\hline Moderate & referent & & referent & \\
\hline Heavier & -2.88 & -3.8 to -1.96 & -1.87 & -3.33 to -0.42 \\
\hline \multicolumn{5}{|c|}{ F: \% protein contribution } \\
\hline Never drinker & -0.44 & -0.95 to 0.06 & 0.00 & -0.52 to 0.52 \\
\hline Former drinker & 0.10 & -0.36 to 0.55 & 0.04 & -0.39 to 0.46 \\
\hline Light & 0.25 & -0.09 to 0.6 & 0.29 & -0.1 to 0.69 \\
\hline Moderate & referent & & referent & \\
\hline Heavier & -1.24 & -1.71 to -0.78 & -0.56 & -1.31 to 0.19 \\
\hline \multicolumn{5}{|c|}{ G: \% carbohydrate contribution } \\
\hline Never drinker & 9.89 & 8.55 to 11.23 & 8.44 & 7.21 to 9.67 \\
\hline Former drinker & 7.37 & 6.55 to 8.19 & 7.82 & 6.6 to 9.04 \\
\hline Light & 6.02 & 5.23 to 6.8 & $\begin{array}{l}5.87 \\
(\mathrm{co})\end{array}$ & $\begin{array}{l}4.8 \text { to } 6.94 \\
\text { ed on next page) }\end{array}$ \\
\hline
\end{tabular}


Table 2. Adjusted associations of average daily drinking volume (drinks/d) with energy intake (kcal/d), macronutrient and sugar contributions (\%) among men and women 20 to 79 years of age, National Health and Nutrition Examination Survey 2003-2012 (continued)

\begin{tabular}{|c|c|c|c|c|}
\hline \multirow[b]{2}{*}{ Variable } & \multicolumn{2}{|c|}{ Men } & \multicolumn{2}{|c|}{ Women } \\
\hline & $\beta$ & $95 \% \mathrm{Cl}$ & $\beta$ & $95 \% \mathrm{Cl}$ \\
\hline Moderate & referent & & referent & \\
\hline Heavier & -6.54 & -7.91 to -5.17 & -6.87 & -9.18 to -4.56 \\
\hline \multicolumn{5}{|c|}{ H: \% carbohydrate (excluding sugar) contribution } \\
\hline Never drinker & 4.76 & 3.67 to 5.85 & 2.61 & 1.57 to 3.65 \\
\hline Light & 2.45 & 2.02 to 2.89 & 1.50 & .67 to 2.33 \\
\hline Moderate & referent & & referent & \\
\hline Heavier & -2.56 & -3.36 to -1.75 & -3.02 & -4.26 to -1.79 \\
\hline \multicolumn{5}{|c|}{ I: \% sugar contribution } \\
\hline Moderate & referent & & referent & \\
\hline Heavier & -3.98 & -5.13 to -2.84 & -3.85 & -5.75 to -1.95 \\
\hline \multicolumn{5}{|c|}{$\begin{array}{l}\text { aData for US men }(n=7,436) \text { and women }(n=6,939) 20 \text { to } 79 \text { years of age. Estimates obtained from a series of sex-stratified multivariable linear regression models, which take into account } \\
\text { survey design and sample weights. Average daily drinking volume calculated as average number of drinks consumed on drinking days (quantity) } \times \text { number of drinking days in the past year/ } \\
365.25 \text { (frequency); light drinking is defined as }<1 \text { drink/d for men and women; moderate drinking is defined as } 1 \text { to } 2 \text { drinks/d for men and } 1 \text { drink/d for women; heavier drinking is } \\
\text { defined as } \geq 3 \text { drinks/d for men and } \geq 2 \text { drinks/d for women. All models adjusted for age, race/ethnicity, education, physical activity level, survey year, chronic disease status, day of recall } 1 \text {, } \\
\text { day of recall 2, potential dietary misreporting and smoking. Continuous dietary outcomes vary for each regression model as follows: A: total energy; B: nonalcoholic energy (food plus } \\
\text { nonalcoholic beverage energy); C: energy from food; } D \text { : energy from nonalcoholic beverages; E: percentage contribution from fat to total energy; F: percentage contribution from protein to } \\
\text { total energy; G: percentage contribution from carbohydrates to total energy; } \mathrm{H} \text { : percentage contribution from carbohydrates (excluding sugar) to total energy; and I: percentage contribution } \\
\text { from sugar to total energy. Macronutrient and sugar intakes were calculated from food and nonalcoholic beverages, but excluded nutrients from alcoholic beverages. Estimates are the } \\
\text { difference in kilocalories per day or percentage contribution compared to moderate drinkers. Boldface indicates statistically significant associations, } P<0.05 \text {. } \\
\text { bexcludes energy from alcoholic beverages. }\end{array}$} \\
\hline
\end{tabular}

from nonalcoholic beverages (model 3). In women, compared with moderate drinkers, differences in WC were $+2.36 \mathrm{~cm}$ $(95 \% \mathrm{CI} 0.8$ to $3.92 \mathrm{~cm})$ in never drinkers and $+4.67 \mathrm{~cm}(95 \% \mathrm{CI}$ 2.95 to $6.39 \mathrm{~cm}$ ) in former drinkers. The direction and significance of estimates were similar for differences in BMI in never and former drinkers compared with moderate drinkers. Associations were strengthened after adjustment for sugar intakes (model 2) and attenuated after adjustment for energy from nonalcoholic energy intake (model 4). In comparison to nonsignificant associations for heavier drinkers in model 1 and model 2, estimates were strengthened and significant for WC ( $\beta 3.00 \mathrm{~cm}, 95 \% \mathrm{CI} 0.66$ to $5.33 \mathrm{~cm}$ ) after adjustment for nonalcoholic energy intake in women (model 4 ).

Average Drinking Quantity. Adjusted differences in WC and BMI of never, former, and current drinkers according to drinks/drinking day by sex are presented in Table 5. In men and women, compared with drinkers in each sex-specific referent subgroup, statistically significant positive differences in WC and BMI were observed among those in the former drinking subgroup (model 1). Associations were strengthened after adjustment for sugar intake (model 2). In men, compared with those in the 1 to 2 drinks/drinking day subgroup, differences in WC and BMI for those in the $\geq 5$ drinks/drinking day subgroup, were $+3.48 \mathrm{~cm}$ (95\% CI 1.97 to
$5.00 \mathrm{~cm}$ ) and +1.39 (95\% CI 0.79 to 2.00 ), respectively (model $1)$. Associations were attenuated after adjustment for sugar intake (model 2) and strengthened after adjustment for nonalcoholic beverages (model 3).

\section{DISCUSSION}

Associations of alcoholic beverage consumption with dietary intake differed according to average daily drinking volume categories. Carbohydrates and sugar from food and nonalcoholic beverages contributed less to the diet composition of heavier drinkers and more to the diet composition of lighter drinkers compared with moderate drinkers. In men, higher drinking quantity (ie, drinks per drinking day) was associated with higher total energy and lower nonalcoholic energy intakes and higher WC and BMI compared with men who consumed lower quantities of alcoholic beverages on days when drinking occurred.

It has been suggested that drinkers might inadequately compensate for alcoholic beverage consumption with altered dietary intake. ${ }^{15}$ Specifically, the results of short-term clinical studies indicate that alcohol consumed before or with a meal can increase food intake and that there might be a lack of compensation for calories consumed from alcohol at later meals. ${ }^{14,15}$ In the current study, heavier-drinking men and women consumed less from nonalcoholic energy sources, 
Table 4. Adjusted associations of average daily drinking volume (drinks/d) with waist circumference (cm) and body mass index (calculated as $\mathrm{kg} / \mathrm{m}^{2}$ ) among men and women 20 to 79 years of age, National Health and Nutrition Examination Survey 2003-2012

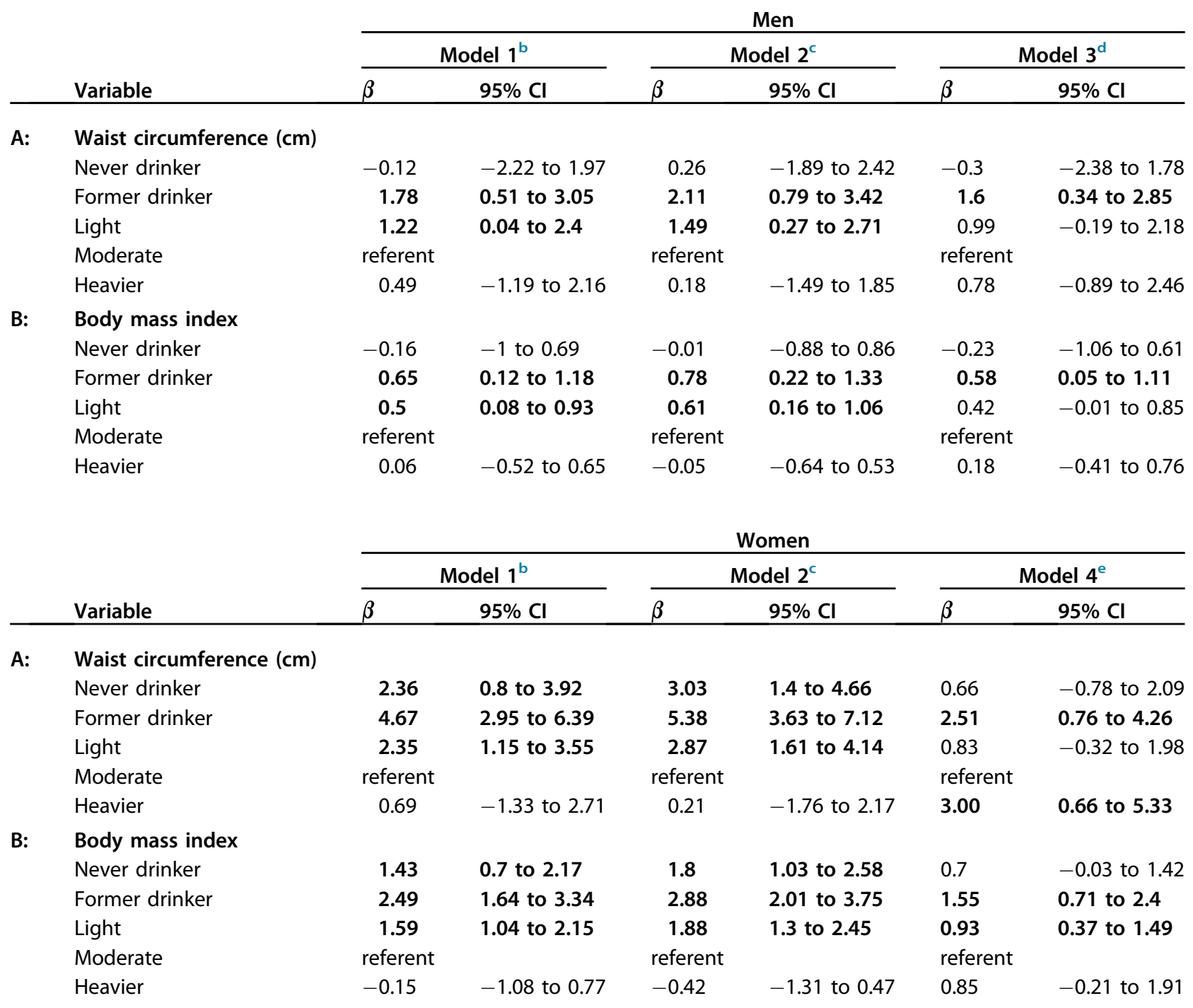

$\bar{a}$ Data for US men ( $n=7,436)$ and women $(n=6,939) 20$ to 79 years of age. $\beta$ coefficients obtained from multivariable linear regression models, which take into account survey design and sample weights. Average daily drinking volume calculated as average number of drinks consumed on drinking days (quantity) $\times$ number of drinking days in the past year/365.25 (frequency); light drinking defined as $<1$ drink/d for men and women; moderate drinking defined as 1 to 2 drinks/d for men and 1 drink/d for women; heavier drinking defined as $\geq 3$ drinks/d for men and $\geq 2$ drinks/d for women. Continuous anthropometric outcomes vary for each regression model as follows: A: waist circumference; $B$ : body mass index. All estimates are the difference in waist circumference and body mass index compared with moderate drinkers. Boldface indicates statistically significant associations, $P<0.05$.

${ }^{b}$ Model 1 was adjusted for age, race/ethnicity, education, marital status, physical activity level, dietary misreporting, survey year, day of recall 1, day of recall 2, daily sedentary time, smoking status, and income.

'Model 2 was adjusted for model 1 covariates plus percentage contribution of sugar from nonalcoholic sources to total energy intake (continuous).

dModel 3 was adjusted for model 1 covariates plus energy from nonalcoholic beverages (continuous).

eModel 4 was adjusted for model 1 covariates plus total nonalcoholic energy (continuous).

whereas former and light drinkers had higher nonalcoholic energy intakes compared with their moderate-drinking counterparts. Total energy intake did not differ by average daily drinking volume among women, but among men, total energy intake was higher for moderate drinkers and lower for former and never drinkers. Within-person variation in compensation behaviors for energy consumed from alcoholic beverages may underlie the differences in dietary intake observed in this study by sex and daily drinking volume. ${ }^{15}$ In addition to short-term clinical studies, epidemiological studies using longitudinal data to examine how diet changes on days when alcohol is consumed are needed to better understand whether compensation behaviors differ by sex and according to average daily drinking volume.

A recent review by Poppit ${ }^{15}$ indicated that drinkers who consumed $\geq 3$ drinks/day might attempt to balance caloric 
Table 5. Adjusted associations of drinking quantity (drinks/drinking day) with waist circumference (cm) and body mass index (calculated as $\mathrm{kg} / \mathrm{m}^{2}$ ) among men and women 20 to 79 years of age, National Health and Nutrition Examination Survey 2003-2012

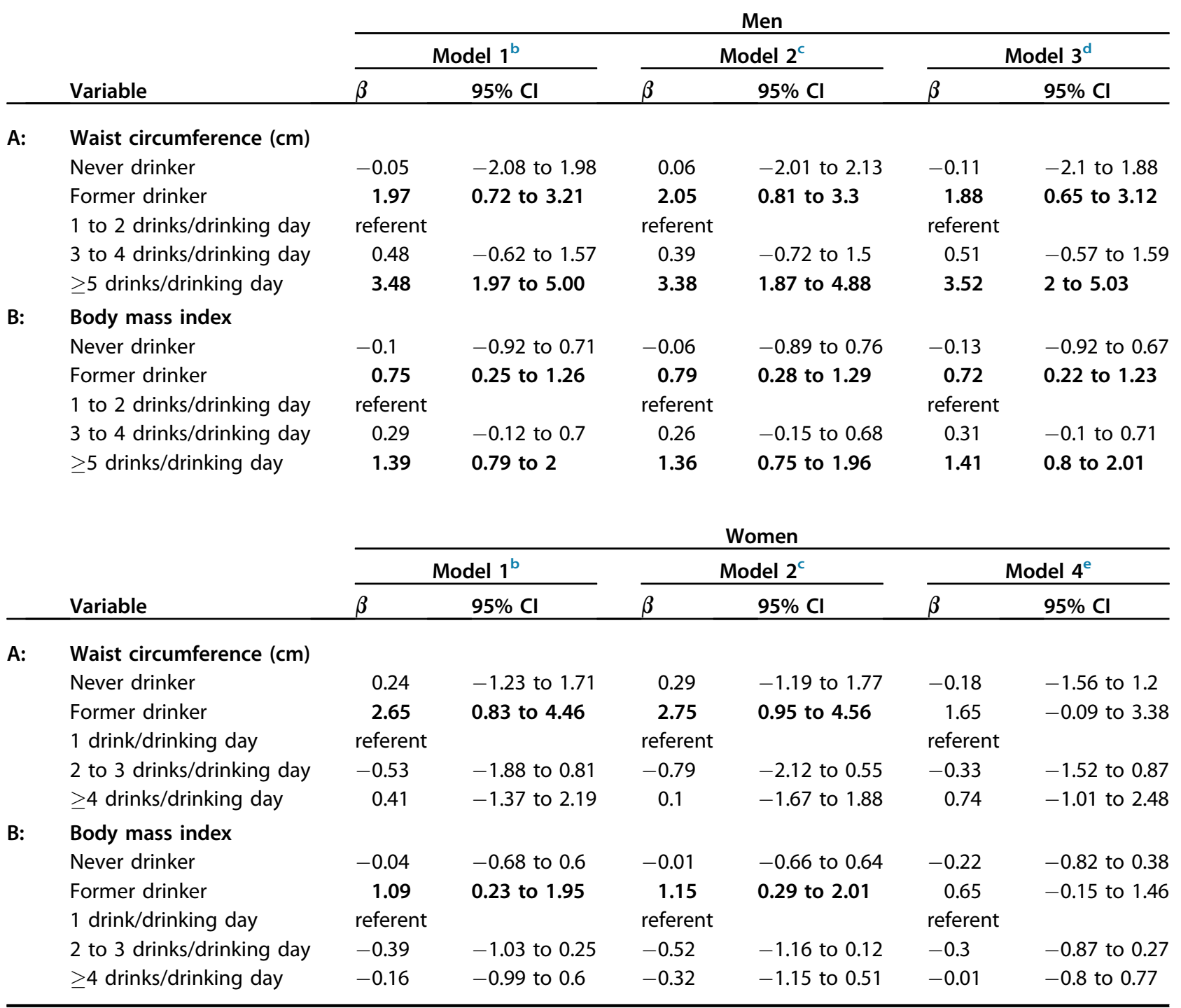

Data for US men $(n=7,436)$ and women $(n=6,939) 20$ to 79 years of age. $\beta$ coefficients obtained from multivariable linear regression models, which take into account survey design and sample weights. Drinking quantity was defined as the number of alcoholic beverages consumed per drinking day. Continuous anthropometric outcomes vary for each regression model as follows: A: waist circumference; B: body mass index. All estimates are the difference in waist circumference and body mass index as compared with each sex-specific referent group. Boldface indicates statistically significant associations, $P<0.05$.

${ }^{b}$ Model 1 was adjusted for age, race/ethnicity, education, marital status, physical activity level, dietary misreporting, survey year, day of recall 1, day of recall 2, daily sedentary time, smoking status, income.

'Model 2 was adjusted for model 1 covariates plus percentage contribution of sugar from nonalcoholic sources to total energy intake (continuous).

${ }^{\mathrm{d}}$ Model 3 was adjusted for model 1 covariates plus energy from nonalcoholic beverages (continuous).

eModel 4 was adjusted for model 1 covariates plus total nonalcoholic energy (continuous).

intake from alcoholic beverages with a decrease in nonalcoholic energy sources. There is a wealth of clinical research linking carbohydrate intake to reduced alcohol intake and sweet preference (among alcoholics). Alcohol and carbohydrates, specifically sugar, may compete for the same neuronal receptors leading to suppressed intake of one nutrient for intake of the other. ${ }^{55,56}$ In the current study, carbohydrates and sugar from nonalcoholic energy sources contributed less to the diet composition of heavier drinkers and more to the diet composition of lighter and nondrinkers compared with moderate drinkers. These findings might suggest that moderate and heavier drinkers decrease carbohydrate- or sugarrich food and beverage intake while light drinkers and nondrinkers do not. To inform nutrition interventions, future research including never and former drinkers should identify specific high-sugar foods (eg, desserts, candies) and beverages (eg, soda) that contribute to altered dietary intake across drinking subgroups. 
When associations of average daily drinking volume with WC and BMI were examined, distinct differences in associations according to nondrinking categories were observed across sex subgroups. Being a former drinker was positively associated with WC and BMI in men and women, yet never drinking was positively associated with WC and BMI in women only. Moderate daily drinking has been inversely associated with measures of obesity in comparison to nondrinking; however, few studies have examined never drinkers and former drinkers as separate nondrinking categories within the same study. ${ }^{19,20,57,58}$ In one study using NHANES data that did examine never and former drinkers, being a current drinker was associated with lower odds of obesity compared with never drinking. ${ }^{3}$ The current study findings support the hypothesis that including former drinkers in the nondrinking referent group may add to inconsistent study findings across the alcohol and obesity literature, particularly among men. Further, when alcohol was defined solely by quantity, positive associations among former drinkers and null associations among never drinkers with WC and BMI were observed for both sex subgroups. Contrasting associations with never drinkers according to the definition of alcoholic beverage consumption indicate that inconsistent definitions of alcoholic beverage consumption across studies likely contribute to the conflicting body of alcohol and obesity literature. Future studies of alcohol and obesity measures should analyze never and former drinkers separately and determine associations of average daily drinking volume and drinking quantity (ie, drinks per drinking day).

Furthermore, the current study findings support the theory that residual confounding by dietary intake can contribute to inconsistencies in the alcohol-obesity literature. This phenomenon does not appear to be dependent on the way in which alcoholic beverage consumption was defined in the current study. For example, the positive association observed between former drinkers with WC and BMI was robust in all models. Yet, the strength and significance of this association differed, depending on whether sugar contribution, nonalcoholic beverages (in men), or total nonalcoholic energy intakes (in women) were included in models. The results of this study underscore the importance of assessing multiple, sexspecific, dietary confounders in associations of alcohol intake with WC and BMI.

Lastly, when alcohol intake was defined as the quantity of drinks/drinking day, positive associations among men who consumed $\geq 5$ drinks/drinking day were observed. These findings are in line with the theory that assessing associations of average daily drinking volume and obesity measures alone can mask associations of drinking quantity with WC and BMI. ${ }^{3,6}$ In studies that have examined relationships with drinking quantity and BMI, positive associations with increasing quantity and higher BMI and increased odds of obesity have been reported. ${ }^{3,6}$ In the current study, men who consumed higher drinking quantities on each drinking day had higher total energy intakes compared with men who drank 1 to 2 drinks/drinking day, which might equate to excess energy intake and ultimately weight gain.10,14,59 However, the cross-sectional nature of this study precludes inferences of causation. The 2015-2020 Dietary Guidelines for Americans describe high-risk drinking in the context of quantity of drinks consumed per drinking day. Specifically, high-risk drinking is defined as $\geq 5$ drinks/ drinking day in men and drinking $\geq 4$ drinks/drinking day in women. ${ }^{37}$ In the current study, high-risk drinking among men was associated with higher total energy intakes, lower nonalcoholic energy intakes and higher WC and BMI compared with men who consumed lower quantities of alcoholic beverages on days when drinking occurred. Future research aimed at elucidating the effects of food and nonalcoholic beverage intake, by sex, on associations between alcoholic beverage consumption and obesity measures among high-risk drinkers in the United States are needed to inform nutrition policy.

\section{Strengths and Limitations}

A main limitation of this study is that nonalcoholic energy intake and macronutrient composition are limited measures of diet, and additional studies are needed to examine the associations between alcoholic beverage consumption and food or beverage groups to better understand dietary differences across drinking subgroups. In addition, the dietary intake data used in this study were obtained from 24-hour recalls, which might be subject to systematic underreporting bias. ${ }^{60}$ Although we attempted to address bias from self-reported energy intake by adjusting for potential dietary misreporting status, the Goldberg method is not without limitation. Identification of potential dietary misreporters was limited by the use of only two 24-hour dietary recalls and self-reported physical activity data; in the absence of objective measures of habitual energy intake, misclassification of potential dietary misreporters is possible. ${ }^{47,61} \mathrm{~A}$ strength of this study was the use of both WC and BMI as obesity measures. The use of varying definitions of anthropometry across studies could be one reason for inconsistent findings in the alcohol-obesity literature. Furthermore, the current study identified drinkers based on the use of the NHANES Alcohol Use Questionnaire, which captured drinking behaviors during the past 12 months. While misclassification of drinkers is still possible, the use of a long-term questionnaire captures drinkers who might have been misclassified as nondrinkers with a shorter-term assessment tool. While analyzing never and former drinkers separately partially addresses concerns regarding heterogeneity in terms of reasons for not drinking, these nondrinking subgroups remain as heterogeneous groups with regard to abstention (eg, health reasons, personal preference, prior problem drinking). In addition, the current study is nationally representative and multiple surveys were pooled to ensure adequate sample size to examine drinking subgroups by sex.

\section{CONCLUSIONS}

Altered food and nonalcoholic beverage intake among drinkers, particularly foods and beverages rich in carbohydrates and/or sugar, should be considered in studies of alcohol intake in relation to WC and BMI. Associations between never and former drinkers with WC and BMI differed whether alcoholic beverage consumption was defined as average daily drinking volume or drinking quantity (ie, drinks per drinking day). Future studies examining the consequences and determinants of dietary intake behaviors in relation to obesity measures in former and high-risk drinking subgroups using nationally representative samples in the United States are needed. 


\section{References}

1. 2015 National Survey on Drug Use and Health: Detailed Tables, Table 2.43B-Alcohol Use in Lifetime, Past Year, and Past Month among Persons Aged 18 or Older, by Demographic Characteristics: Percentages, 2014 and 2015. Rockville, MD: Substance Abuse and Mental Health Services Administration; 2016. https://www.samhsa. gov/data/sites/default/files/NSDUH-DetTabs-2015/NSDUH-DetTabs2015/NSDUH-DetTabs-2015.pdf. Published September 8, 2016. Accessed August 28, 2017.

2. Early release of selected estimates based on data from the 2015 National Health Interview Survey. http://www.bobmorrison.org/ wp-content/uploads/2017/01/cdc-report-on-uninsured-and-otherpopulation-stats.pdf. Published 2016. Accessed August 28, 2017.

3. Arif AA, Rohrer JE. Patterns of alcohol drinking and its association with obesity: Data from the third National Health and Nutrition Examination Survey, 1988-1994. BMC Public Health. 2005;5(1):1-6.

4. Traversy G, Chaput J-P. Alcohol consumption and obesity: An update. Curr Obes Rep. 2015;4(1):122-130.

5. Poli A, Marangoni F, Avogaro A, et al. Moderate alcohol use and health: A consensus document. Nutr Metab Cardiovasc Dis. 2013;23(6):487-504.

6. Breslow RA, Smothers BA. Drinking patterns and body mass index in never smokers National Health Interview Survey, 1997-2001. Am J Epidemiol. 2005;161(4):368-376.

7. Dawson DA. Methodological issues in measuring alcohol use. Alcohol Res Health. 2003;27(1):18-29.

8. Breslow RA, Guenther PM, Juan W, Graubard BI. Alcoholic beverage consumption, nutrient intakes, and diet quality in the US adult population, 1999-2006. J Am Diet Assoc. 2010;110(4):551-562.

9. Breslow RA, Guenther PM, Smothers BA. Alcohol drinking patterns and diet quality: The 1999-2000 National Health and Nutrition Examination Survey. Am J Epidemiol. 2006;163(4):359-366.

10. Kim SY, Breslow RA, Ahn J, Salem N Jr. Alcohol consumption and fatty acid intakes in the 2001-2002 National Health and Nutrition Examination Survey. Alcohol Clin Exp Res. 2007;31(8):1407-1414.

11. Liangpunsakul S. Relationship between alcohol intake and dietary pattern: Findings from NHANES III. World J Gastroenterol. 2010;16(32):4055

12. Colditz GA, Giovannucci E, Rimm EB, et al. Alcohol intake in relation to diet and obesity in women and men. Am J Clin Nutr. 1991;54(1):49-55.

13. Gruchow HW, Sobocinski KA, Barboriak JJ, Scheller JG. Alcohol consumption, nutrient intake and relative body weight among US adults. Am J Clin Nutr. 1985;42(2):289-295.

14. Yeomans MR. Alcohol, appetite and energy balance: Is alcohol intake a risk factor for obesity? Physiol Behav. 2010;100(1):82-89.

15. Poppitt SD. Beverage consumption: Are alcoholic and sugary drinks tipping the balance towards overweight and obesity? Nutrients. 2015;7(8):6700-6718.

16. Breslow RA, Mukamal KJ. Measuring the burden-Current and future research trends: Results from the NIAAA Expert Panel on Alcohol and Chronic Disease Epidemiology. Alcohol Res Curr Rev. 2013;35(2):250259.

17. Sayon-Orea C, Martinez-Gonzalez MA, Bes-Rastrollo M. Alcohol consumption and body weight: A systematic review. Nutr Rev. 2011;69(8):419-431.

18. Fisher M, Gordon T. The relation of drinking and smoking habits to diet: The Lipid Research Clinics Prevalence Study. Am J Clin Nutr. 1985;41(3):623-630.

19. Williamson DF, Forman MR, Binkin NJ, Gentry EM, Remington PL, Trowbridge FL. Alcohol and body weight in United States adults. Am J Public Health. 1987;77(10):1324-1330.

20. Sherwood N, Jeffery R, French S, Hannan P, Murray D. Predictors of weight gain in the Pound of Prevention study. Int $J$ Obesity. 2000;24(4):395-403.

21. Suter PM, Tremblay A. Is alcohol consumption a risk factor for weight gain and obesity? Crit Rev Clin Lab Sci. 2005;42(3):197-227.

22. Sluik D, Bezemer R, Sierksma A, Feskens E. Alcoholic beverage preference and dietary habits: A systematic literature review. Crit Rev Food Sci Nutr. 2016;56(14):2370-2382.

23. Fillmore KM, Stockwell T, Chikritzhs T, Bostrom A, Kerr W. Moderate alcohol use and reduced mortality risk: Systematic error in prospective studies and new hypotheses. Ann Epidemiol. 2007;17(5 suppl):S16-S23.

24. Fillmore KM, Kerr WC, Stockwell T, Chikritzhs T, Bostrom A. Moderate alcohol use and reduced mortality risk: Systematic error in prospective studies. Addict Res Theory. 2006;14(2):101-132.

25. Centers for Disease Control and Prevention, National Center for Health Statistics. National Health and Nutrition Examination Survey 2003-2004. Questionnaire Files. Alcohol use [data, docs, questionnaire]. http://wwwn.cdc.gov/Nchs/Nhanes/2003-2004/ALQ_C.htm. Published December 2006. Accessed June 12, 2015.

26. Centers for Disease Control and Prevention, National Center for Health Statistics. National Health and Nutrition Examination Survey 2005-2006. Questionnaire files. Alcohol use [data, docs, questionnaire (ages 20+)]. http://wwwn.cdc.gov/Nchs/Nhanes/ 2005-2006/ALQ_D.htm. Published March 2008. Accessed June $12,2015$.

27. Centers for Disease Control and Prevention, National Center for Health Statistics. National Health and Nutrition Examination Survey 20092010. Questionnaire files. Alcohol use [data, docs, questionnaire (ages 20+)]. http://wwwn.cdc.gov/Nchs/Nhanes/2009-2010/ALQ_F.htm. Published January 2012. Accessed June 12, 2015.

28. Centers for Disease Control and Prevention, National Center for Health Statistics. National Health and Nutrition Examination Survey 2011-2012. Questionnaire files. Alcohol use [data, docs, questionnaire]. http://wwwn.cdc.gov/Nchs/Nhanes/2011-2012/ALQ_G.htm. Published October 2013. Accessed June 12, 2015.

29. Centers for Disease Control and Prevention. National Health and Nutrition Examination Survey 2007-2008 data documentation, codebook, and frequencies. https://wwwn.cdc.gov/Nchs/Nhanes/ 2007-2008/ALQEE.htm. Published September 2009. Accessed June 23, 2015.

30. Centers for Disease Control and Prevention. National Health and Nutrition Examination Survey Data, 2005-2006. https://wwwn.cdc. gov/nchs/nhanes/ContinuousNhanes/Default.aspx?BeginYear=2005. Accessed January 22, 2015.

31. Centers for Disease Control and Prevention. National Health and Nutrition Examination Survey Data, 2009-2010. https://wwwn.cdc. gov/nchs/nhanes/continuousnhanes/default.aspx?BeginYear=2009. Accessed June 23, 2015.

32. Centers for Disease Control and Prevention. National Health and Nutrition Examination Survey Data, 2011-2012. 2015. https://wwwn. cdc.gov/nchs/nhanes/continuousnhanes/default.aspx?BeginYear= 2011. Accessed January 22, 2015.

33. Centers for Disease Control and Prevention. National Health and Nutrition Examination Survey Data, 2003-2004. https://wwwn.cdc. gov/nchs/nhanes/continuousnhanes/default.aspx?BeginYear=2003. Published January 2002. Accessed June 23, 2015.

34. Centers for Disease Control and Prevention, National Center for Health Statistics. National Health and Nutrition Examination Survey, 2007-2008. https://wwwn.cdc.gov/nchs/nhanes/continuousnhanes/ default.aspx?BeginYear=2007. Accessed June 23, 2015.

35. Centers for Disease Control and Prevention, National Center for Health Statistics. General Information About the Mobile Examination Center (MEC) examination data. 2015. https://www.cdc.gov/nchs/ data/nhanes/nhanes_03_04/exam_c_generaldoc.pdf. Accessed June 23, 2015.

36. Butler L, Poti JM, Popkin BM. Trends in energy intake from alcoholic beverages among US adults by sociodemographic characteristics, 1989-2012. J Acad Nutr Diet. 2016;116(7):1087-1100.e6.

37. US Department of Health and Human Services and US Department of Agriculture. 2015-2020 Dietary Guidelines for Americans. 8th ed. https://health.gov/dietaryguidelines/2015/guidelines/. Published December 2015. Accessed October 16, 2017.

38. US Department of Agriculture, Agricultural Research Service. USDA National Nutrient Database for Standard Reference, Release 26. Beltsville, MD: US Department of Agriculture, Agricultural Research Service, National Nutrient, Beltsville Human Nutrition Research Center, Nutrient Data Laboratory; 2013.

39. Guenther PM, Bowman SA, Goldman JD. Alcoholic beverage consumption by adults 21 years and over in the United States: Results from the National Health and Nutrition Examination Survey, 20032006: Technical report. https://www.cnpp.usda.gov/sites/default/ files/dietary_guidelines_for_americans/AlcoholicBeveragesConsumption. pdf. Published March 2010. Accessed August 2017. 
40. Sayon-Orea C, Bes-Rastrollo M, Nunez-Cordoba JM, BasterraGortari FJ, Beunza JJ, Martinez-Gonzalez MA. Type of alcoholic beverage and incidence of overweight/obesity in a Mediterranean cohort: The SUN project. Nutrition. 2011;27(7-8):802-808.

41. Brandhagen M, Forslund HB, Lissner L, et al. Alcohol and macronutrient intake patterns are related to general and central adiposity. Eur J Clin Nutr. 2012;66(3):305-313.

42. MacInnis RJ, Hodge AM, Dixon HG, et al. Predictors of increased body weight and waist circumference for middle-aged adults. Public Health Nutr. 2014;17(5):1087-1097.

43. Liangpunsakul S. Relationship between alcohol intake and dietary pattern: Findings from NHANES III. World J Gastroenterol. 2010;16(32):4055-4060.

44. Austin GL, Krueger PM. Increasing the percentage of energy from dietary sugar, fats, and alcohol in adults is associated with increased energy intake but has minimal association with biomarkers of cardiovascular risk. J Nutr. 2013;143(10):1651-1658.

45. Sanghvi A, Redman LM, Martin CK, Ravussin E, Hall KD. Validation of an inexpensive and accurate mathematical method to measure longterm changes in free-living energy intake. Am J Clin Nutr. 2015;102(2):353-358.

46. Murakami K, Livingstone MBE. Prevalence and characteristics of misreporting of energy intake in US adults: NHANES 2003-2012. Br J Nutr. 2015;114(08):1294-1303.

47. Mendez MA, Popkin BM, Buckland G, et al. Alternative methods of accounting for underreporting and overreporting when measuring dietary intake-obesity relations. Am J Epidemiol. 2011;173(4):448458.

48. Black AE. The sensitivity and specificity of the Goldberg cut-off for EI BMR for identifying diet reports of poor validity. Eur J Clin Nutr 2000;54(5):395-404.

49. Black AE. Critical evaluation of energy intake using the Goldberg cutoff for energy intake:basal metabolic rate. A practical guide to its calculation, use and limitations. Int J Obes Relat Metab Disord. 2000;24(9):1119-1130.

50. Frankenfield DC. Bias and accuracy of resting metabolic rate equations in non-obese and obese adults. Clin Nutr. 2013;32(6):976-982.
51. Food and Agriculture Organization of the United Nations. Human Energy Requirements: Report of a Joint FAO/WHO/ONU Expert Consultation. Rome, Italy: Food and Agriculture Organization of the United Nations; 2001.

52. Bull FC, Maslin TS, Armstrong T. Global physical activity questionnaire (GPAQ): Nine country reliability and validity study. J Phys Act Health. 2009;6(6):790-804.

53. Stata Statistical Software [computer program]. Release 14. College Station, TX: StataCorp LP; 2015.

54. UCLA Statistical Consulting Group, UCLA Institute for Digital Research and Education. Statistical Computing Seminars, Applied Survey Data Analysis in STATA 9. https://stats.idre.ucla.edu/stata/ seminars/applied-svy-stata9/. Published 2015. Accessed March 12 2015.

55. Kampov-Polevoy AB, Garbutt JC, Janowsky DS. Association between preference for sweets and excessive alcohol intake: A review of animal and human studies. Alcohol Alcohol. 1999;34(3):386-395.

56. Krahn D, Grossman J, Henk H, Mussey M, Crosby R, Gosnell B. Sweet intake, sweet-liking, urges to eat, and weight change: Relationship to alcohol dependence and abstinence. Addict Behav. 2006;31(4):622631.

57. Liu S, Serdula MK, Williamson DF, Mokdad AH, Byers T. A prospective study of alcohol intake and change in body weight among US adults. Am J Epidemiol. 1994;140(10):912-920.

58. Rohrer JE, Rohland BM, Denison A, Way A. Frequency of alcohol use and obesity in community medicine patients. BMC Fam Pract. 2005;6(1):1

59. Yeomans MC, Caton S, Hetherington MM. Alcohol and food intake. Curr Opin Nutr Metab Care. 2003;6(6):639-644.

60. Trabulsi J, Schoeller DA. Evaluation of dietary assessment in struments against doubly labeled water, a biomarker of habitual energy intake. Am J Physiol Endocrinol Metab. 2001;281(5):E891E899.

61. Tooze JA, Krebs-Smith SM, Troiano RP, Subar AF. The accuracy of the Goldberg method for classifying misreporters of energy intake on a food frequency questionnaire and 24-hour recalls: Comparison with doubly labeled water. Eur J Clin Nutr. 2012;66(5):569.

\section{AUTHOR INFORMATION}

L. Butler is a postdoctoral research associate, Department of Nutrition, University of North Carolina Gillings School of Global Public Health, Chapel Hill, and Department of Psychology, University of Florida, Gainesville. B. M. Popkin is a W. R. Kenan Jr Distinguished Professor and J. M. Poti is a research assistant professor, Department of Nutrition, University of North Carolina Gillings School of Global Public Health, Chapel Hill.

Address correspondence to: Jennifer M. Poti, PhD, University of North Carolina at Chapel Hill, 2214 McGavran-Greenberg Hall, Campus Box 7461, Chapel Hill, NC 27599. E-mail: poti@unc.edu

\section{STATEMENT OF POTENTIAL CONFLICT OF INTEREST}

No potential conflict of interest was reported by the authors.

\section{FUNDING/SUPPORT}

Funding for this study comes from the Robert Wood Johnson Foundation (RWJF 67506, 68793, 70017, 71837), the National Institutes of Health (NIH R01DK098072), a National Institutes of Health National Research Service Award (NIH-NRSA 2T32DK007686-21), and the Carolina Population Center (CPC 5 R24 HD050924).

\section{ACKNOWLEDGEMENTS}

The authors wish to thank Phil Bardsley, PhD, for exceptional assistance with data management and programming and Frances $\mathrm{L}$. Dancy for administrative assistance. 


\section{Supplemental Methods and Analyses}

The revised Goldberg method was used to identify implausible energy intakes and categorize adults as potential dietary underreporters, over-reporters, or accurate reporters, as described elsewhere. ${ }^{47-49}$ Briefly, for adults in energy balance, the ratio of reported total energy intake to basal metabolic rate (BMR) should be equivalent to physical activity level (PAL). Age, weight, and height were used to calculate BMR using sex-specific Mifflin-St Jeor equations. ${ }^{50}$ National Health and Nutrition Examination Survey (NHANES) 2003-2006 collected PA data using an interviewer-administered PA questionnaire that queried on intensity, duration, and frequency of PA over the past 30 days. In 2007, the Global Physical Activity Questionnaire replaced the previously used NHANES PA questionnaire. ${ }^{51}$ The Global Physical Activity Questionnaire collects data on recreational, work, and travel activities. PAL was categorized using total metabolic equivalent of task (MET) minutes per week of PA and assigned as sedentary $=1.4$, light active $=1.55$, and active $=1.75$ based on Food and Agriculture Organization guidelines. ${ }^{51,52}$ Confidence limits were calculated for each individual, allowing reported energy intake to BMR ratio to differ from reported PAL by 1.5 standard deviations. ${ }^{47,49}$ Adults with reported energy intake to BMR ratio below or above these confidence limits were classified as dietary under-reporters and over-reporters, respectively.

When used as a covariate in linear regression models, PAL was categorized according to the number of days during which a participant self-reported engaging in vigorous and/or total PA and MET minutes per week of PA. NHANES reports the number of days during which each participant engaged in various PA during a typical week; however, it is not possible to know whether a participant engaged in more than one type of activity per day. Total PA was defined as the total instances per week of selfreported vigorous and/or moderate PA and/or walking or biking. Respondents were categorized as follows: "high" ( $\geq 3$ days of vigorous PA and $\geq 1,500 \mathrm{MET}$-min/wk of PA or $\geq 7$ instances/wk of total PA and $\geq 3,000 \mathrm{MET}$-min/wk of PA), or "moderate" ( $\geq 3$ days of vigorous PA for $\geq 20$ minutes or $\geq 5$ days of self-reported moderate PA [eg, biking and walking] for $\geq 30$ minutes or $\geq 5$ instances/wk of total PA and $\geq 600 \mathrm{MET}$-min/wk of PA); any respondent who did not meet the criteria for "high" or "moderate" PA was categorized in the "low" PA category.

Figure. Approach used to categorize US adults aged 20 to 79 years who participated in the 2003-2012 National Health and Nutrition Examination Survey by potential dietary misreporting status and by physical activity level. 
Table 3. Adjusted associations of drinking quantity (drinks/drinking day) with energy intake (kcal/d), macronutrient and sugar contributions (\%) among men and women 20 to 79 years of age, National Health and Nutrition Examination Survey 2003-2012 ${ }^{a}$

Aariable

Never drinker

Former drinker

1 to 2 drinks/drinking day

3 to 4 drinks/drinking day

$\geq 5$ drinks/drinking day

B: Nonalcoholic energy $(\mathrm{kcal} / \mathrm{d})^{\mathrm{b}}$

Never drinker

Former drinker

1 to 2 drinks/drinking day

3 to 4 drinks/drinking day

$\geq 5$ drinks/drinking day

\section{C: Food energy (kcal/d) ${ }^{\text {b }}$}

Never drinker

Former drinker

1 to 2 drinks/drinking day

3 to 4 drinks/drinking day

$\geq 5$ drinks/drinking day

D: Nonalcoholic beverage energy $(\mathrm{kcal} / \mathrm{d})^{\mathrm{b}}$

Never drinker

Former drinker

1 to 2 drinks/drinking day

3 to 4 drinks/drinking day

$\geq 5$ drinks/drinking day

\section{E: $\%$ fat contribution}

Never drinker

Former drinker

1 to 2 drinks/drinking day

3 to 4 drinks/drinking day

$\geq 5$ drinks/drinking day

\begin{tabular}{ll} 
& Men \\
\hline$\beta$ & $95 \% \mathrm{Cl}$
\end{tabular}

Variable

A: Total energy ( $\mathrm{kcal} / \mathrm{d}$ )

$\begin{array}{rll}-110 & -183 \text { to }-\mathbf{3 7} & \text { Never drinker } \\ -20 & -71 \text { to } 31 & \text { Former drinker } \\ \text { referent } & & 1 \text { drink/drinking day } \\ 46 & -5 \text { to } 96 & 2 \text { to } 3 \text { drinks/drinking day } \\ 134 & 69 \text { to } 200 & \geq 4 \text { drinks/drinking day }\end{array}$

\section{B: Nonalcoholic energy (kcal/d) ${ }^{\text {b }}$}

$\begin{array}{rl}-35 & -109 \text { to } 38 \\ 72 & 23 \text { to } 121\end{array}$

referent

$-65-119$ to -12

$-81-139$ to -22

$-56-118$ to 6

$41-8$ to 91

referent

$-55-104$ to -6

$-71-127$ to -15

$\begin{array}{cl}20 & -14 \text { to } 55 \\ 31 & 7 \text { to } 54 \\ \text { eferent } & \\ -11 & -34 \text { to } 13 \\ -9 & -35 \text { to } 16 \\ -1.4 & -2.36 \text { to }-.45 \\ .77 & .06 \text { to } 1.49\end{array}$

referent

$-.75-1.5$ to -.01

$-1.51-2.28$ to -.73
Never drinker

Former drinker

1 drink/drinking day

2 to 3 drinks/drinking day

$\geq 4$ drinks/drinking day

\section{C: Food energy (kcal/d) ${ }^{\text {b }}$}

Never drinker

Former drinker

1 drink/drinking day

2 to 3 drinks/drinking day

$\geq 4$ drinks/drinking day

D: Nonalcoholic beverage energy $(\mathrm{kcal} / \mathrm{d})^{\mathrm{b}}$

Never drinker

Former drinker

1 drink/drinking day

2 to 3 drinks/drinking day

$\geq 4$ drinks/drinking day

\section{E: $\%$ fat contribution}

Never drinker

Former drinker

1 drink/drinking day

2 to 3 drinks/drinking day

$\geq 4$ drinks/drinking day
Women

$95 \% \mathrm{Cl}$

$\beta \quad 95 \% \mathrm{Cl}$

\begin{tabular}{|c|c|}
\hline 13 & -24 to 51 \\
\hline $\begin{array}{l}42 \\
\text { referent }\end{array}$ & 3 to 80 \\
\hline 37 & 5 to 68 \\
\hline 108 & 48 to 168 \\
\hline 34 & -4 to 73 \\
\hline $\begin{array}{l}77 \\
\text { referent }\end{array}$ & 38 to 116 \\
\hline-15 & -48 to 18 \\
\hline-17 & -82 to 48 \\
\hline 11 & -27 to 49 \\
\hline $\begin{array}{l}41 \\
\text { referent }\end{array}$ & 2 to 80 \\
\hline 16 & -19 to 51 \\
\hline-15 & -71 to 41 \\
\hline 23 & 4 to 42 \\
\hline $\begin{array}{l}36 \\
\text { referent }\end{array}$ & 10 to 63 \\
\hline-31 & -49 to -13 \\
\hline-2 & -37 to 33 \\
\hline-.6 & -1.31 to .11 \\
\hline $\begin{array}{c}.22 \\
\text { referent }\end{array}$ & -.56 to 1 \\
\hline .18 & -.46 to .82 \\
\hline-.79 & -1.84 to .26 \\
\hline
\end{tabular}

(continued on next page) 
Table 3. Adjusted associations of drinking quantity (drinks/drinking day) with energy intake (kcal/d), macronutrient and sugar contributions (\%) among men and women 20 to 79 years of age, National Health and Nutrition Examination Survey 2003-2012 ${ }^{\mathrm{a}}$ (continued)

\begin{tabular}{|c|c|c|c|c|c|}
\hline \multirow[b]{2}{*}{$\underline{\text { Variable }}$} & \multicolumn{2}{|c|}{ Men } & \multirow[b]{2}{*}{ Variable } & \multicolumn{2}{|c|}{ Women } \\
\hline & $\beta$ & $95 \% \mathrm{Cl}$ & & $\beta$ & $95 \% \mathrm{Cl}$ \\
\hline F: \% protein contribution & & & F: \% protein contribution & & \\
\hline Never drinker & -.64 & -1.16 to -.12 & Never drinker & -.25 & -.68 to .17 \\
\hline Former drinker & -.04 & -.45 to .37 & Former drinker & -.2 & -.49 to .1 \\
\hline 1 to 2 drinks/drinking day & referent & & 1 drink/drinking day & referent & \\
\hline 3 to 4 drinks/drinking day & -.34 & -.63 to -.04 & 2 to 3 drinks/drinking day & .02 & -.31 to .34 \\
\hline$\geq 5$ drinks/drinking day & -.32 & -.64 to .01 & $\geq 4$ drinks/drinking day & -.42 & -.97 to .14 \\
\hline G: \% carbohydrate contribution & & & G: \% carbohydrate contribution & & \\
\hline Never drinker & 5.17 & 3.87 to 6.48 & Never drinker & 2.12 & 1.15 to 3.09 \\
\hline Former drinker & 3.04 & 2.23 to 3.85 & Former drinker & 1.83 & .82 to 2.85 \\
\hline 1 to 2 drinks/drinking day & referent & & 1 drink/drinking day & referent & \\
\hline 3 to 4 drinks/drinking day & -3.3 & -4.21 to -2.4 & 2 to 3 drinks/drinking day & -3.1 & -4.04 to -2.15 \\
\hline$\geq 5$ drinks/drinking day & -5.11 & -6.17 to -4.06 & $\geq 4$ drinks/drinking day & -5.02 & -6.66 to -3.39 \\
\hline H: \% carbohydrate (excluding sugar) contribution & & & H: \% carbohydrate (excluding sugar) contribution & & \\
\hline Never drinker & 2.71 & 1.59 to 3.83 & Never drinker & 1.08 & .35 to 1.81 \\
\hline Former drinker & 1.08 & .55 to 1.61 & Former drinker & .27 & -.46 to .99 \\
\hline 1 to 2 drinks/drinking day & referent & & 1 drink/drinking day & referent & \\
\hline 3 to 4 drinks/drinking day & -1.33 & -1.92 to -.75 & 2 to 3 drinks/drinking day & -.46 & -.99 to .07 \\
\hline$\geq 5$ drinks/drinking day & -2.74 & -3.31 to -2.17 & $\geq 4$ drinks/drinking day & -2.13 & -3.07 to -1.18 \\
\hline I: \% sugar contribution & & & I: \% sugar contribution & & \\
\hline Never drinker & 2.47 & 1.29 to 3.66 & Never drinker & 1.04 & .06 to 2.02 \\
\hline Former drinker & 1.96 & 1.15 to 2.77 & Former drinker & 1.57 & .54 to 2.59 \\
\hline 1 to 2 drinks/drinking day & referent & & 1 drink/drinking day & referent & \\
\hline 3 to 4 drinks/drinking day & -1.97 & -2.69 to -1.25 & 2 to 3 drinks/drinking day & -2.63 & -3.51 to -1.76 \\
\hline$\geq 5$ drinks/drinking day & -2.38 & -3.28 to -1.47 & $\geq 4$ drinks/drinking day & -2.9 & -4.34 to -1.45 \\
\hline
\end{tabular}

${ }^{a}$ Data for US men $(n=7,436)$ and women $(n=6,939) 20$ to 79 years of age. Estimates obtained from sex-stratified multivariable linear regression models, which take into account survey design and sample weights. Drinking quantity was defined as the number of alcoholic beverages consumed per drinking day (drinks/drinking day). All models adjusted for age, race/ethnicity, education, physical activity level, survey year, chronic disease status, day of recall 1, day of recall 2, potential dietary misreporting and smoking. Continuous dietary outcomes vary for each regression model as follows: A: total energy; B: nonalcoholic energy (food plus nonalcoholic beverage energy); C: energy from food; D: energy from nonalcoholic beverages. E: percentage contribution from fat to total energy; F: percentage contribution from protein to total energy; G: percentage contribution from carbohydrates to total energy; H: percentage contribution from carbohydrates (excluding sugar) to total energy: I: percentage contribution from sugar to total energy. Macronutrient and sugar intakes were calculated from food and nonalcoholic beverages but excluded nutrients from alcoholic beverages. Estimates are the difference in kilocalories per capita per day (kcal/d) or percentage contribution (\%) compared to each sex-specific referent group. Boldface indicates statistically significant associations, $P<0.05$.

Excludes energy from alcoholic beverages. 